\title{
Controlling the Variable of Pressure in the Production of Test Footwear Impressions
}

Kevin J. Farrugia ${ }^{\text {a b }}$, Philip Riches ${ }^{c}$, Helen Bandey ${ }^{d}$, Kathleen Savage ${ }^{a}$, Niamh NicDaéid ${ }^{\text {a }}$

${ }^{a}$ Centre for Forensic Science, WestCHEM, Department of Pure and Applied Chemistry, University of Strathclyde, Glasgow, G1 1XW, UK

${ }^{\mathrm{b}}$ School of Contemporary Sciences, Division of Forensic and Bio Sciences, University of Abertay, Bell Street, Dundee, DD1 1HG, UK

${ }^{\mathrm{c}}$ Department of Bioengineering, University of Strathclyde, Wolfson Building, 106 Rottenrow, Glasgow, G4 0NW, UK

${ }^{\mathrm{d}}$ Centre for Applied Science and Technology [formerly HOSDB], Home Office Science, Woodcock Hill, Sandridge, St. Albans, AL4 9HQ, UK

\section{* CORRESPONDING AUTHORS}

Niamh Nic Daéid

Centre for Forensic Science, WestCHEM, Department of Pure and Applied Chemistry,

University of Strathclyde, Glasgow, G1 1XW, UK

n.nicdaeid@strath.ac.uk 


\begin{abstract}
Footwear impression lifting and enhancement techniques may be affected by several variables introduced during the production of test footwear impressions, thus limiting the usefulness of enhancement technique comparisons and the results obtained. One such variable is the force applied when the impressed mark is being made. Producing consistent test impressions for research into footwear enhancement techniques would therefore be beneficial. This study was designed to control pressure in the production of test footwear impressions when mimicking a stamping action. Twenty-seven volunteers were asked to stamp on two different surfaces and the average stamping force was recorded.

Information from the data obtained was used to design and build a mechanical device which could be calibrated to consistently deliver footwear impressions with the same force onto a receiving surface. Preliminary experiments using this device and different contaminants on the footwear sole have yielded consistent and repeatable impressions. Controlling the variable of pressure for the production of test impressions in this study demonstrated that the differences observed were visual (due to the amount of contaminant transferred and subsequent enhancement) and did not affect the replication of outer sole characteristics. This paper reports the development of the device and illustrates the quality of the impressions produced.
\end{abstract}

Keywords: footwear impressions, stamping, pressure, blood, acid yellow 7, luminol 


\section{INTRODUCTION}

It can be argued that robust comparisons of footwear enhancement techniques, both for the purposes of technique development and for the evaluation of the quality of the enhanced impression, can only be reliably made if the test footwear impressions have been prepared in the same way, thus minimising the effect of different variables. The pressure of the footwear sole on the receiving surface as the footwear impression is made is one such variable and while this is only one of the factors which need to be considered, its effect may be critical to the successful comparison of enhancement techniques. [1]

Other variables introduced during the preparation of test footwear impressions include the amount and composition of contaminant (e.g. blood, mud, dust, etc.) on the footwear sole prior to transfer to the receiving surface, the amount of contaminant that is transferred to the footwear sole, the nature of the receiving surface (porosity, texture etc.) and colour perception (for example the human eye is relatively insensitive to dim red light and as a result, weakly fluorescing impressions may be missed unless the eyes are dark adapted for a period of about 30 minutes prior to observation [2]).

Controlling the amount of contaminant on a footwear sole and the subsequent amount transferred to a receiving surface can be challenging, though some methodologies have been suggested to limit the effect of these variables. This has included the preparation of soil and distilled water mixtures to study muddy impressions [3, 4] and the use of tissue soaked with a few millimetres of blood as a reservoir for the consistent application of blood to a shoe sole for the study of impressions in blood [5]. It is, however, unclear as to how, or if, the impressions produced during the testing phase of these studies were repeatable and the effect of pressure on the repeatability of the impression was not considered. In addition, impressions were prepared using part of a shoe sole measuring $4 \times 4 \mathrm{~cm}$ rather than a whole shoe [3-5]. Many studies [6-16] relating to footwear impression enhancement have focused on the chemical mechanisms underlying specific techniques or the enhancement efficiency with little or no obvious regard to potential variables in the preparation of test footwear impressions. 
This work addresses this issue in part and was designed to develop a method to control the pressure used in the production of test footwear impressions for a stamping action. While it is recognised that it may be impossible to replicate a given footwear impression encountered within an operational context, measures such as those presented here, can be taken in order to limit the variables involved in producing such impressions for research, development or reconstruction purposes. In this work a stamping motion was studied and a mechanical test rig developed to replicate the average force delivered onto a flat surface through such an action. A stamping motion was studied to reflect casework involving stamping on a victim where there is a high potential that footwear impressions on fabric will be made. The objective of this work was the comparison of different enhancement reagents to enhance footwear impressions, rather than directly mimic operational conditions normally encountered. Furthermore, this study does not attempt to evaluate the ability of characteristics (both manufactured and acquired) to be reproduced for comparison purposes. 


\section{MATERIALS AND METHODS}

Stamping experiments were conducted using pressure plates (Kistler 9281C, Amherst, NY) coupled to a computer. The generated data was processed using a Vicon Workstation (Version 5.2.4) capable of measuring force in the $\mathrm{x}, \mathrm{y}$ and $\mathrm{z}$ direction.

After receiving ethical approval for the study, twenty-seven volunteers (12 male and 15 female) were asked to stamp onto a block of material. Two recipient surfaces were used: high density foam and a block of wood. In both cases, the substrates were placed over pressure plates connected to a computer which was set to produce a reading of the applied force in Newtons $(\mathrm{N})$ at 1/3000 second intervals $(3000 \mathrm{~Hz})$. High density foam was utilised to mimic the elastic action of stamping on a victim's torso and wood was used for comparison of the same action onto an unyielding surface. Each volunteer stamped 10 times on each surface using their preferred leg giving a total of 270 sets of data per surface. The volunteers were instructed to stamp once the start button on the software was pressed by the investigator. There was a short time delay from when the software started to record the data to when the volunteer actually stamped and this was reflected in the output generated. t-tests were performed on the generated data using SPSS (version 16) to check for statistically significant differences between genders and surfaces.

Data generated from these experiments was used to design a stamping rig for the preparation of test footwear impressions at a constant pressure. The ability of the test rig to recreate the appropriate average stamping forces demonstrated by the volunteers was validated by recording data from 50 repeat tests of the developed equipment where the 'foot' was dropped from the appropriate height (as suggested by tests with the live volunteers) onto high density foam covering the Kistler pressure plate.

Finally, different contaminants (e.g. blood, mud, etc.) were then used to check the performance of the stamping rig where fabric was utilised as the receiving substrate for the test footwear impressions. The fabric was positioned on top of high density foam to mimic the elastic action of stamping on a victim's torso. 
Figure 1 illustrates the sole pattern utilised in the study (Etnies brand, EU size 42, UK size 8) whereas Table 1 defines the manually introduced characteristics by means of a knife and scissors.

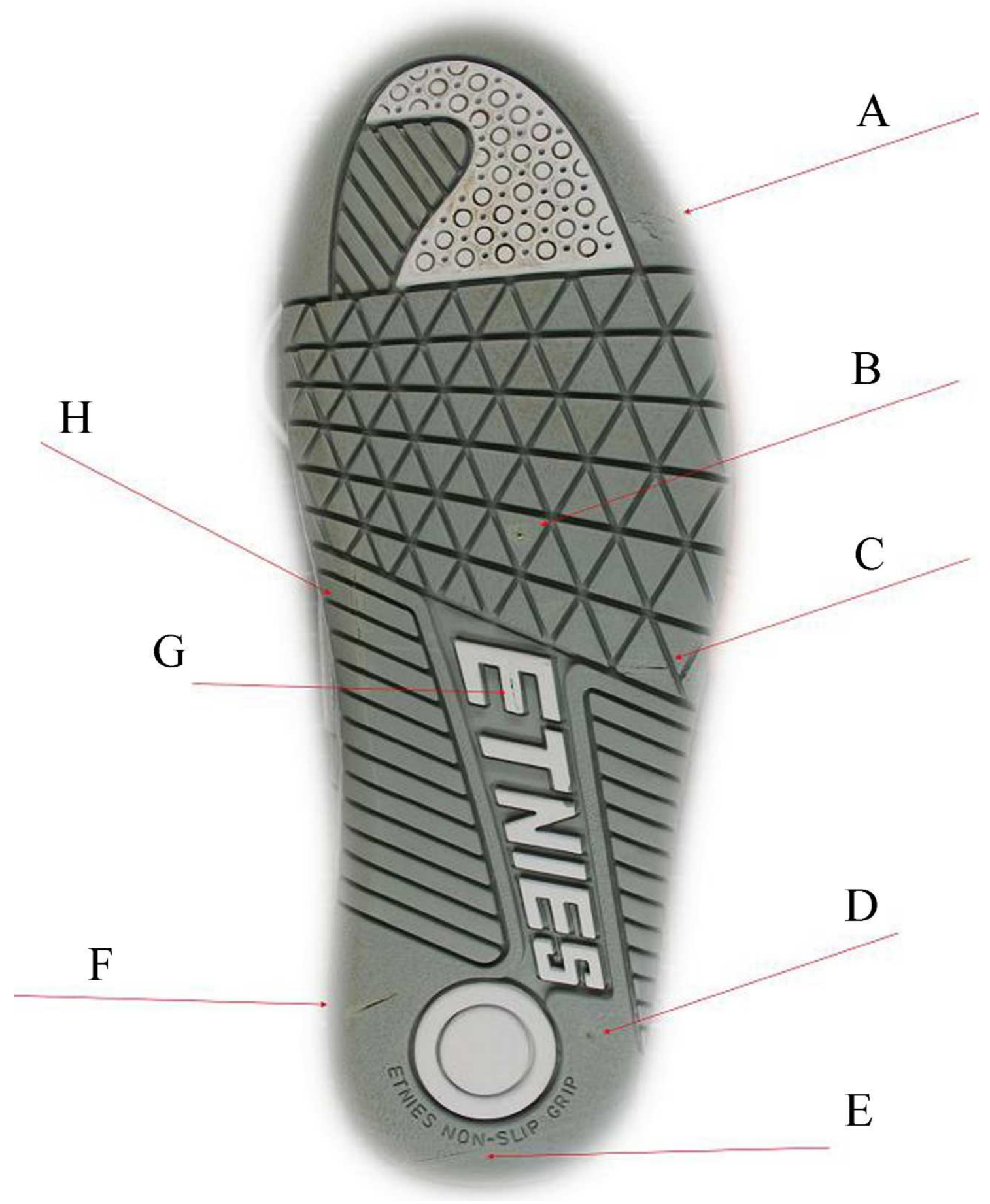

Figure 1 - Introduced carvings and indentation on the footwear sole 


\begin{tabular}{|c|c|}
\hline Characteristic & Description \\
\hline A & Piece of sole scratched off \\
\hline B & Piercing \\
\hline C & Deep scratch indentation \\
\hline D & Piercing \\
\hline E & Light scratch indentation \\
\hline F & Deep scratch indentation \\
\hline G & Deep scratch indentation \\
\hline H & Light scratch indentation \\
\hline
\end{tabular}

\section{RESULTS AND DISCUSSION}

Force measurements indicated that the average stamping force produced by volunteers was $2560 \mathrm{~N}$ with a minimum of $634 \mathrm{~N}$ and a maximum of $5263 \mathrm{~N}$. This variability could potentially be due to differences in height, weight, strength and gender of volunteers as well as fatigue experienced by each individual as the tests progressed. Figures 2 and 3 show the force profiles for volunteer F1 when stamping on foam and wood respectively. The profiles are similar in shape, though foam shows a dampening effect, presumably due to elasticity of the material and its ability to readily deform on application of a force, thereby absorbing some of its magnitude. This resilience can be defined as the elasticity of a material that enables it to resume its original shape after being bent, stretched or compressed [17]. Examples of resilient materials include carpets, grass and skin. All force profiles obtained from volunteers were similar in shape to those revealed in figures 2 and 3. 


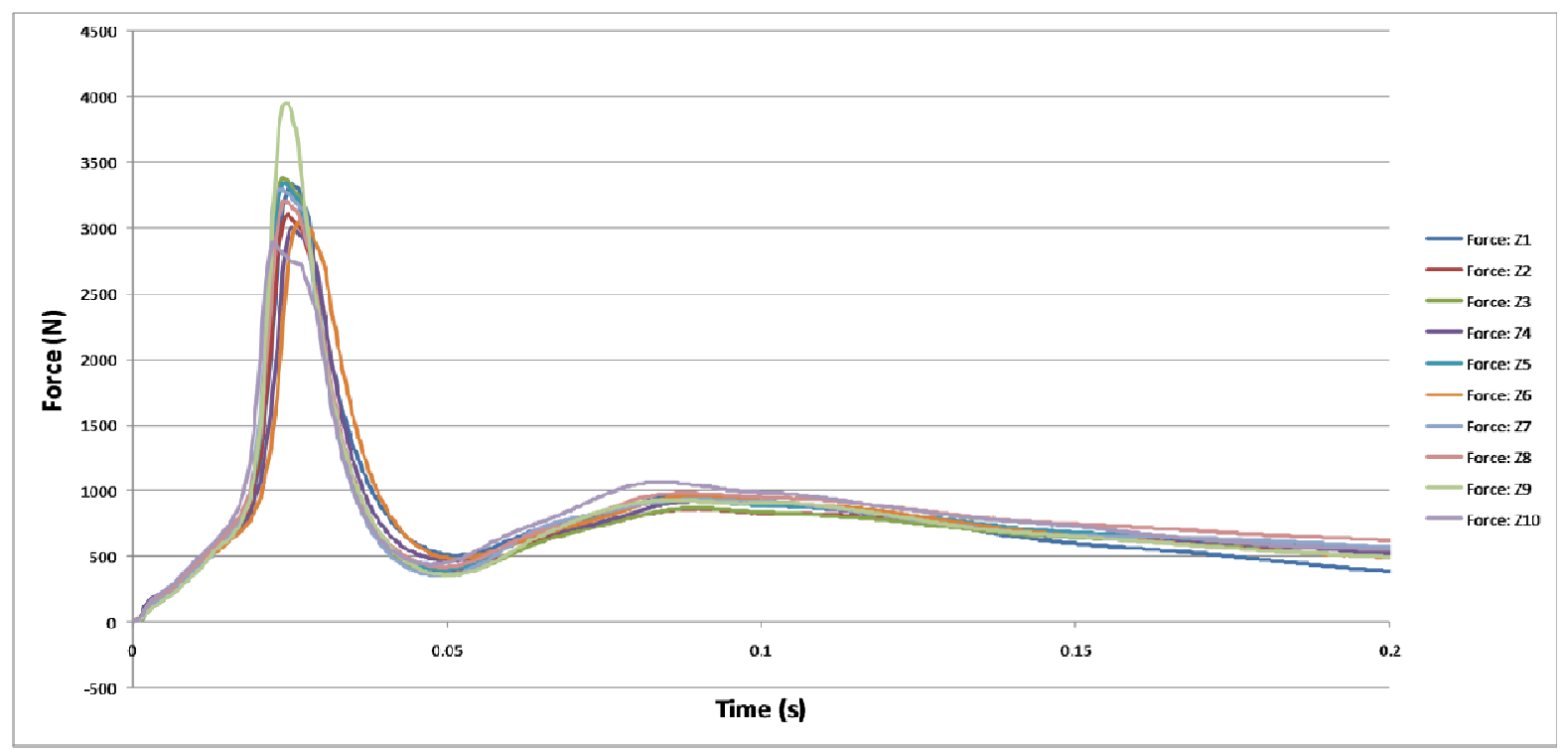

Figure 2 - Force $(\mathrm{N})$ against time (s) for volunteer F1 on foam

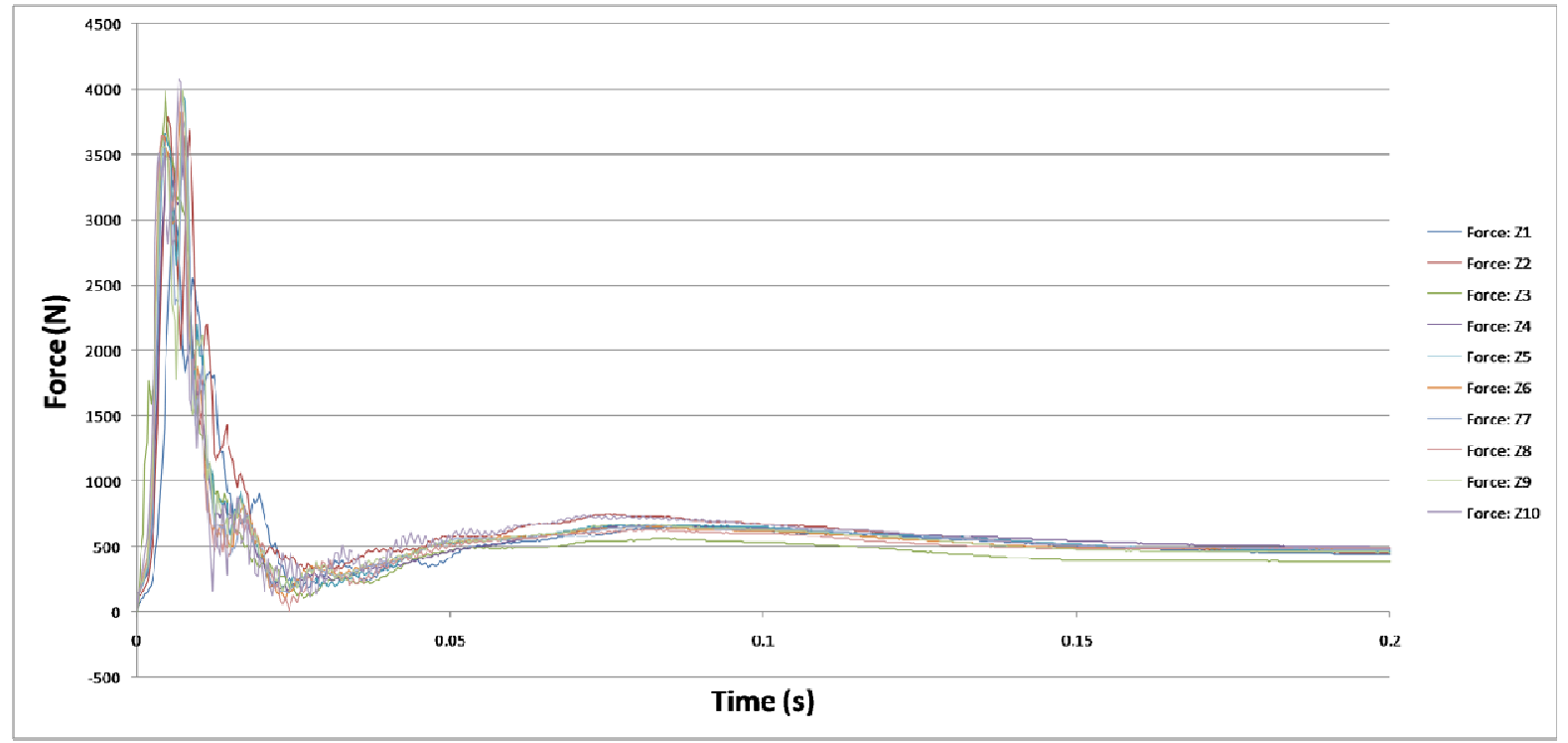

Figure 3 - Force (N) against time (s) for volunteer F1 on wood

The average force of 10 stamps from each volunteer for each receiving surface (foam and wood) was calculated and is presented in tables 2 . 
Table 2 -Average force in Newtons (N) and standard deviation on foam and wood for females and males

\begin{tabular}{|c|c|c|c|c|c|c|}
\hline Subject & \multicolumn{3}{|c|}{ Foam } & \multicolumn{3}{c|}{ Wood } \\
\hline & $\begin{array}{c}\text { Average } \\
\text { Force (N) }\end{array}$ & $\begin{array}{c}\text { Standard } \\
\text { Deviation }\end{array}$ & $\begin{array}{c}\text { Rel. Standard } \\
\text { Deviation (\%) }\end{array}$ & $\begin{array}{c}\text { Average } \\
\text { Force (N) }\end{array}$ & $\begin{array}{c}\text { Standard } \\
\text { Deviation }\end{array}$ & $\begin{array}{c}\text { Rel. Standard } \\
\text { Deviation (\%) }\end{array}$ \\
\hline Females & 2303 & 324 & 16 & 2735 & 294 & 12 \\
\hline Males & 2882 & 357 & 13 & 3257 & 333 & 11 \\
\hline
\end{tabular}

The data obtained was analysed using SPSS statistical software (version 16.0). The Kolmogorov Smirnov test was applied to confirm that the force delivered onto the receiving surface by each volunteer was normally distributed. Figures 4 and 5 illustrate the range of forces obtained for each volunteer on foam and wood.

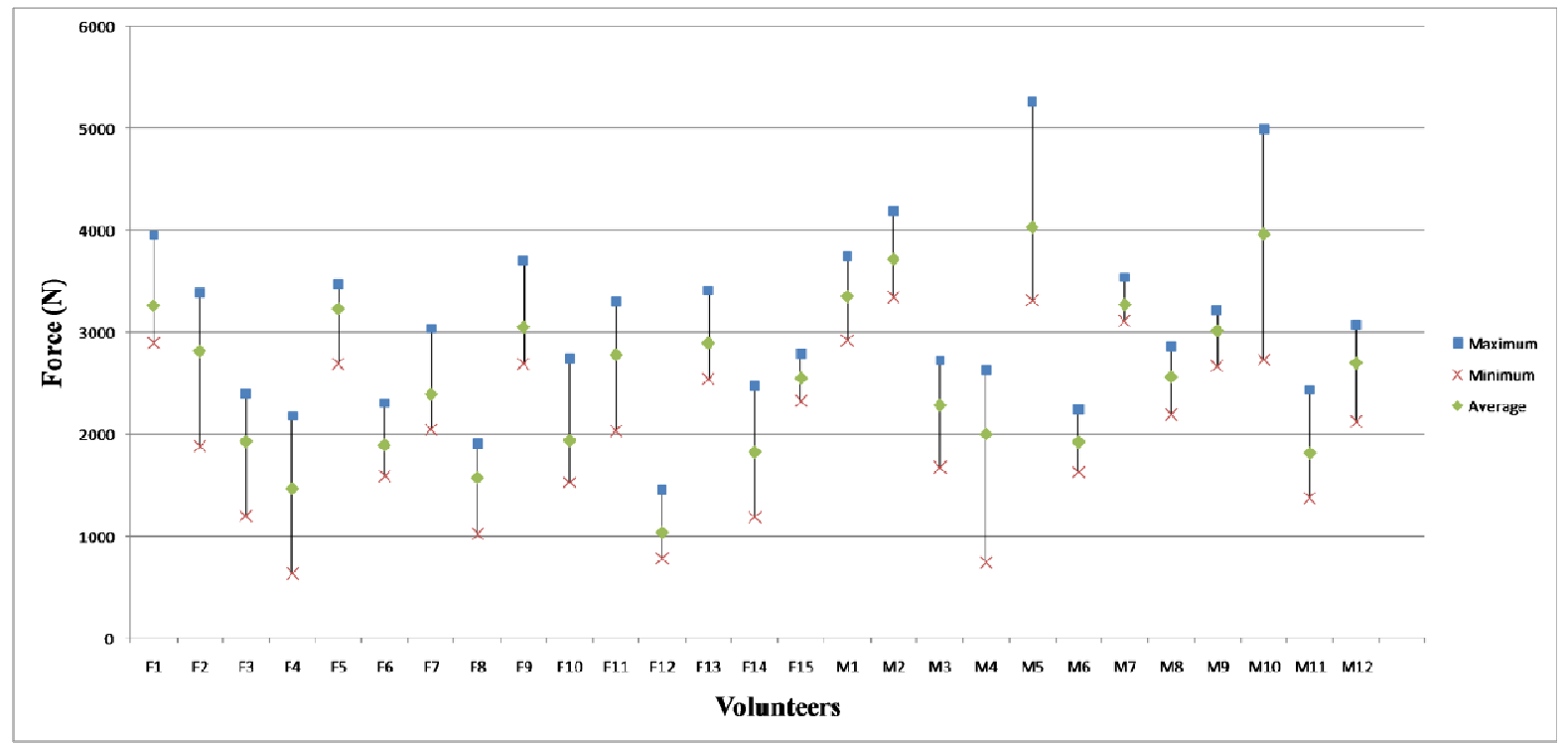

Figure 4 - Force $(\mathrm{N})$ against volunteers showing the maximum, minimum and average forces on foam

t-tests were also carried out to test for statistical differences in the means between the following four sets of data: 1) female and male foam results; 2) female and male wood results; 3) female foam and female wood results and 4) male foam and male wood results. No significant statistical differences were observed between any of the data sets tested. In light of the variations between volunteers and the general spread of the data it was decided to use $3,500 \mathrm{~N}$ as the target force for delivery by the developed footwear rig to simulate a realistic hard (above average) stamping action. 


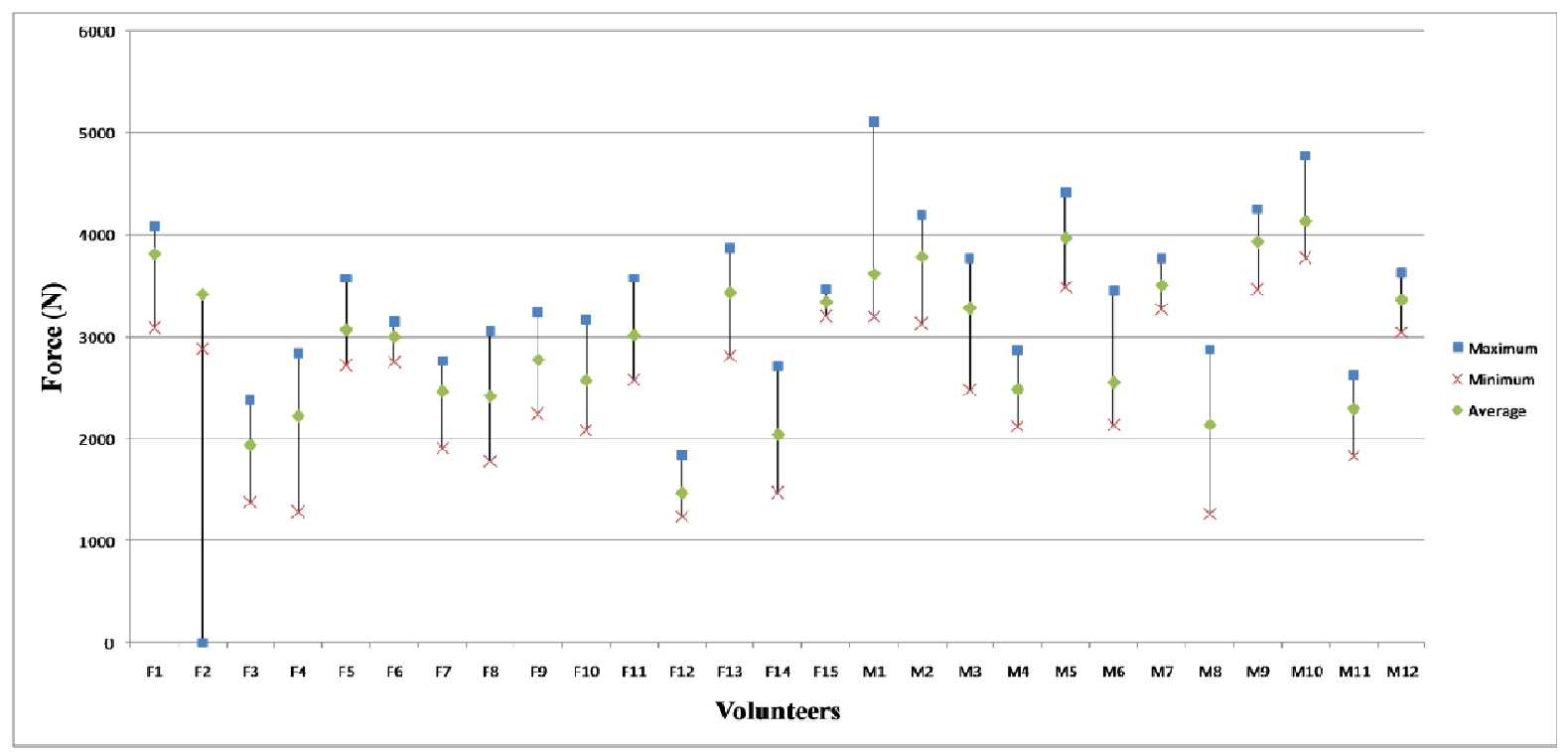

Figure 5 - Force $(\mathrm{N})$ against volunteers showing the maximum, minimum and average forces on wood

The construction of a mechanically based stamping rig designed to deliver a constant force onto a recipient horizontal surface required the application of some basic kinematic concepts presented in equations 1 and 2 [18]. At ground level (height $h=0$ ), an object has no potential energy (PE) [equation 1] but has kinetic energy (KE) [equation 2]. In contrast, at a height $\mathrm{h}$, an object has PE but no KE.

$$
\begin{array}{ll}
P E=m g h & \text { [equation 1] } \\
K E=\frac{1}{2} m v^{2} & \text { [equation 2] }
\end{array}
$$

where $\mathrm{m}$ is mass in $\mathrm{kg}$

$\mathrm{g}$ is the acceleration due to gravity in $\mathrm{m} / \mathrm{s}^{2}=9.81 \mathrm{~m} / \mathrm{s}^{2}$

$\mathrm{h}$ is the height in $\mathrm{m}$

$\mathrm{v}$ is the velocity in $\mathrm{m} / \mathrm{s}$

The principle of conservation of energy states that energy cannot be created nor destroyed, thus in its most simplistic form, potential energy and kinetic energy equate to each other. Thus equation 1 and 2 become:

$$
P E=m g h=K E=\frac{1}{2} m v^{2}
$$




$$
\begin{aligned}
& \frac{1}{2} m v^{2}=m g h \\
& v^{2}=\frac{2 m g h}{m}=2 g h \\
& v=\sqrt{2 g h}
\end{aligned}
$$

[equation 3]

For a straight line collision or impact, the average impact force multiplied by the distance (or height) gives the change in kinetic energy [equation 4].

$$
\text { Work Done }=\Delta K E=F_{a v} d \quad \text { [equation 4] }
$$

where

$\mathrm{F}_{\mathrm{av}}$ is the average force in $\mathrm{N}$

$\mathrm{d}$ is the distance in $\mathrm{m}$

Equation 4 demonstrates that if the penetration of the surface stamped upon is large, then the impact force is going to be smaller. For high density foam (soft surface and thus greater penetration) the impact force is expected to be smaller than for a wooden surface. Equation 4 provides the average impact force $\left(\mathrm{F}_{\mathrm{av}}\right)$ delivered, however, the peak impact force $\left(\mathrm{F}_{\mathrm{p}}\right)$ is required for the accurate determination of the height from which a fixed mass needs to be dropped in order to replicate the desired average force. Under theoretical conditions, if an impact force of approximately 3,500N (obtained from stamping preliminary work with live volunteers) is required on a surface that has a penetration of approximately $0.03 \mathrm{~m}$ (the estimated penetration obtained from deflection of the foam upon the action of stamping), then 66.85 Joules $(\mathrm{J})$ of energy is needed assuming the stamping contact follows a $1^{\text {st }}$ approximation sinusoidal curve [19] and that air friction is negligible.

Work done $=\int_{0}^{0.1} F d x$

[equation 5]

where $F_{p}=3500 \sin (2 \pi f t)[f=5 \mathrm{~Hz}$ if the sine curve cycle has a time of $0.2 \mathrm{~s})$

$\int_{0}^{0.1} F_{p} d t=\int_{0}^{0.1} 3500 \sin (2 \pi f t)=\left[-\frac{3500}{2 \pi f t} \cos (2 \pi f t)\right]=222.80 \mathrm{Ns}$ 
$\mathrm{F}_{\mathrm{av}}=\frac{222.8}{0.1}=2228 \mathrm{~J}$

Work Done $=F_{a v} d=2228 \times 0.03=66.85 \mathrm{~J}$

Given that $\mathrm{PE}=\mathrm{KE}, \mathrm{PE}=\mathrm{mgh}$ and $\mathrm{m}=10.2 \mathrm{kgs}$

$\mathrm{h}=\frac{P E}{m g}=\frac{66.84}{10.2 \times 9.81}$

$\mathrm{h}=0.67 \mathrm{~m}$

For practical purposes, a $10.2 \mathrm{~kg}$ weight was inserted on top of the foot which would then be dropped from a height of $0.67 \mathrm{~m}$ to deliver the desired force onto a recipient horizontal surface. The test rig was constructed using the above calculations and consisted of a long rod with a foot-shaped attachment fitted with a shoe at one end. The $10.2 \mathrm{~kg}$ weight placed on top of the 'foot' acted as the driving force for the stamping mechanism. The rig was designed to facilitate variation in height (and therefore force) and a simple release system controlled the dropping of the weight. A height of $0.64 \mathrm{~m}$ delivered the desired force $(3500 \mathrm{~N})$ onto a horizontal high density foam surface. The rig was designed to be sturdy and was fitted with anti-sliding legs to help prevent sudden movements or sliding. The rig is shown in figure 6. The rig was calibrated and validated using pressure plates (as previously described) to measure the force applied to the surface. Statistical analyses of the results were carried out to validate the repeatability of the results obtained as the primary requirement of the rig was to deliver footwear impressions of consistent quality.

\section{Repeatability of the Stamping Force}

Repeatability of the force of the delivered stamp was assessed by undertaking 50 repeat tests of the equipment where the 'foot' was dropped from the same height $(0.64 \mathrm{~m}$ gave a force of around $3500 \mathrm{~N}$ ) onto high density foam covering the Kistler pressure plate. The height of $0.64 \mathrm{~m}$ only differed slightly from the calculated $0.67 \mathrm{~m}$. The data obtained from this study was analysed and found to be reproducible with an average of $3548 \mathrm{~N}$ and a relative standard deviation of $1.6 \%$ across 50 measurements. Figure 7 shows the force profile of five of the test stamps. This graph is very similar to those obtained from live volunteers, though an additional smaller peak at time $=0.5 \mathrm{~s}$ is observed, most likely linked to the bounce effect of the foot from the rig on the high density foam. 


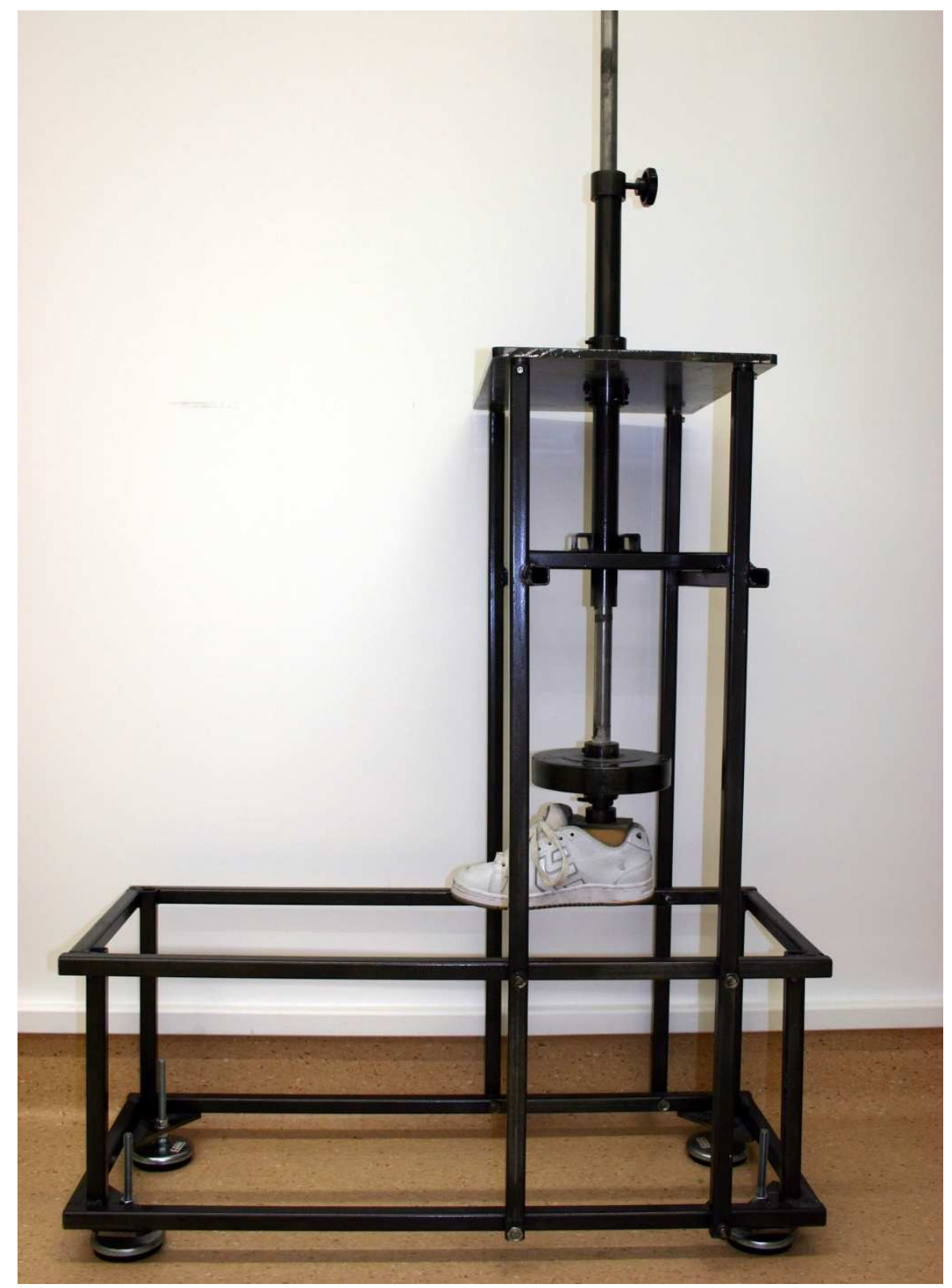

Figure 6 - The stamping rig designed for the study

\section{Footwear Impression Examples}

Repeatable results were obtained during performance trials of the test rig prior to use in research investigating the enhancement of footwear impressions in blood, urine and mud which is reported elsewhere [20-24]. The series of enhanced impressions in figure 8 depict the clarity and uniformity of the impressions created by the apparatus, as compared to the impressions created without the use of the apparatus (figure 9). The latter series demonstrated variability in terms of general appearance and also exhibited signs of movement during the impressions making process. Similar research has been recently published on the use of a 
fingerprint sampler to produce consistent and reproducible fingermark depositions [25]. A recent study has shown that the pressure used for the deposition of a fingerprint is related to the quality of enhancement achieved [26]. The variable of force would therefore interfere with a successful comparison of different enhancement techniques. Another study described a method to control and calculate the amount of amino acid in a particular deposition so that comparison of fingerprint enhancement techniques is more robust [27].

Table 3- Forces recorded in 50 repetitive stamping trials

\begin{tabular}{|l|l|l|}
\hline \multicolumn{3}{|c|}{ Force in Newtons (N) } \\
\hline 3507 & 3460 & 3555 \\
\hline 3529 & 3455 & 3594 \\
\hline 3593 & 3512 & 3561 \\
\hline 3564 & 3438 & 3541 \\
\hline 3563 & 3457 & 3516 \\
\hline 3504 & 3458 & 3479 \\
\hline 3563 & 3500 & 3527 \\
\hline 3589 & 3614 & 3554 \\
\hline 3564 & 3675 & 3579 \\
\hline 3625 & 3575 & 3532 \\
\hline 3569 & 3612 & 3535 \\
\hline 3606 & 3556 & 3524 \\
\hline 3573 & 3529 & 3576 \\
\hline 3507 & 3583 & 3490 \\
\hline 3604 & 3536 & 3506 \\
\hline 3617 & 3664 & 3472 \\
\hline 3562 & 3595 & \\
\hline & & \\
\hline
\end{tabular}

Table shows the 50 force (Newtons) values where the 'foot' from the test rig was dropped from the same height for 50 times 


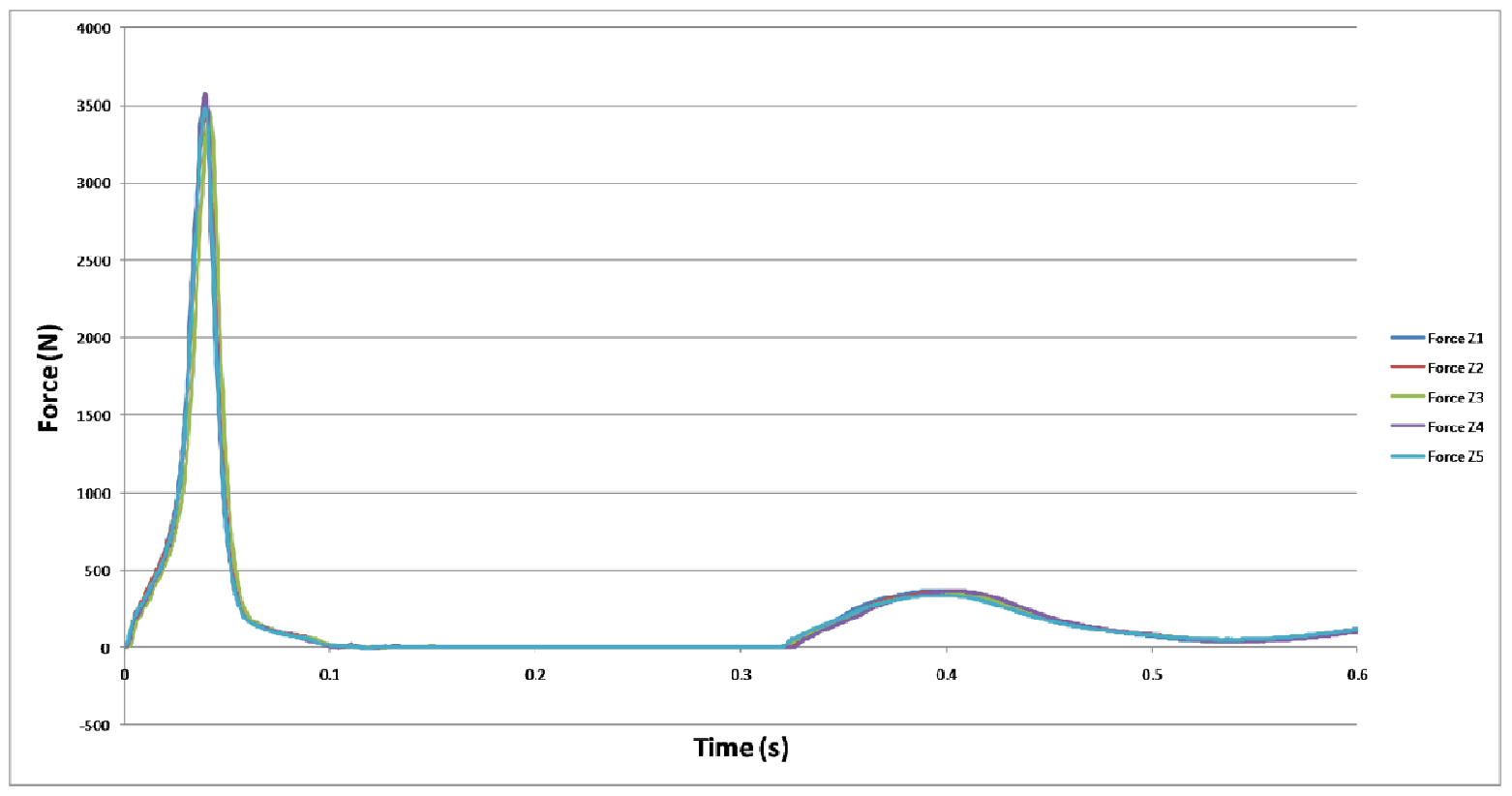

Figure 7 - Force (N) against time (s) obtained from five randomly selected rig trials
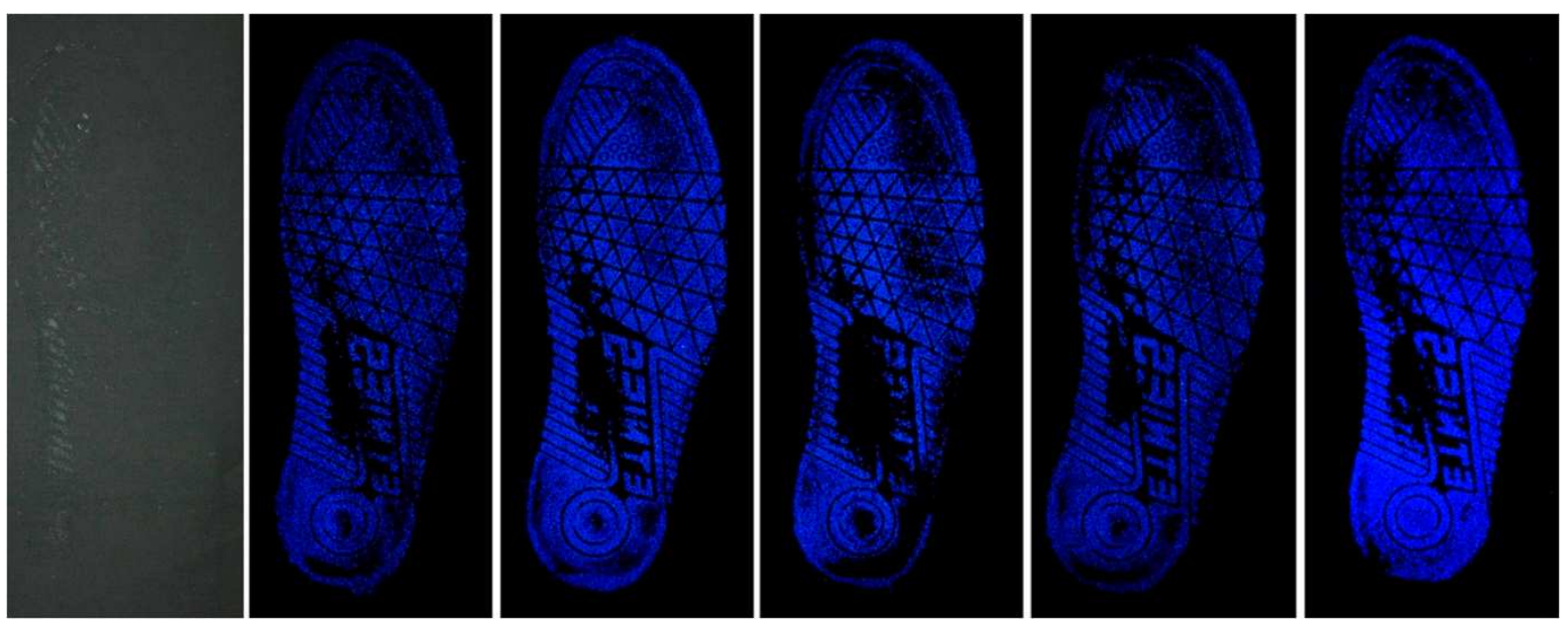

Figure 8 - An unenhanced footwear impression in blood on black cotton (far left) followed by 5 samples of enhanced footwear impressions in blood on same fabric using luminol (all impressions prepared using the stamping rig)

As luminol is not sensitive to small changes in the concentration of blood, repetitive impressions in blood on black cotton were prepared using the protein stain acid yellow 7 (AY7) as recommended by the Centre for Applied Science and Technology (CAST) [formerly the Home Office Scientific Development Branch (HOSDB)] [28]. Protein stains, compared to luminol, are more sensitive to minute changes in the concentration of blood [29, 30]. A series of impressions in blood were prepared at three different forces using the 
footwear rig: 3500N (High); 2500N (Medium) and 1100N (Low). Figure 10 shows the enhancement of these impressions in blood using AY7, excited with blue light (352-509nm) using a Mason Vactron Quaser 40 and viewed with a yellow/orange filter $(510 \mathrm{~nm})$. The figure shows that blood impressions prepared with a high force $(3,500 \mathrm{~N})$ (figure 10c) and subsequent enhancement with AY7 provided stronger fluorescence than impressions in blood prepared with medium $(2500 \mathrm{~N})$ (figure $10 \mathrm{~b}$ ) or low force $(1100 \mathrm{~N})$ (figure 10a). This highlights the effect of pressure when evaluating different enhancement techniques.
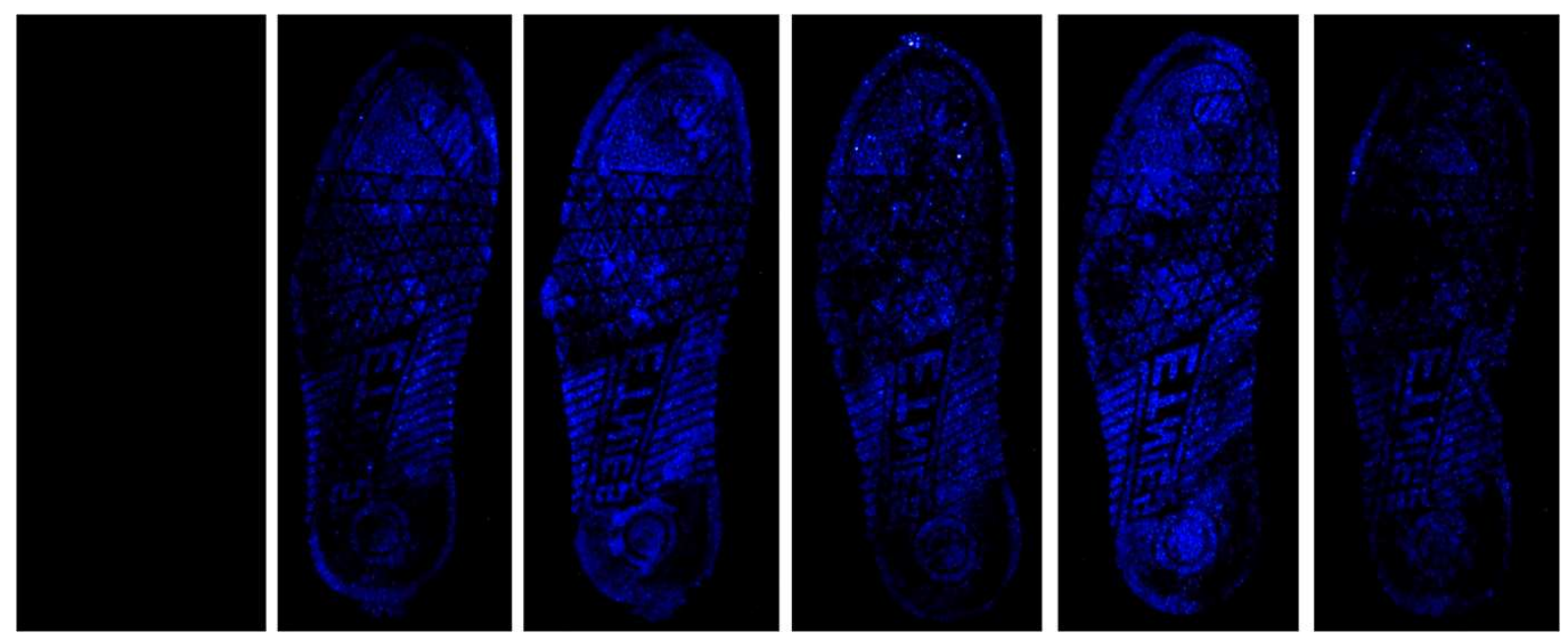

Figure 9 - An unenhanced footwear impression in blood on black cotton (far left) followed by 5 samples of enhanced footwear impressions in blood on same fabric using luminol (all impressions prepared without using the stamping rig)

Further work to demonstrate the repeatability of preparing test impressions by a mechanical rig involved the preparation of two diminishing series of impressions in blood on black cotton. These impressions were aged for seven days before treatment with AY7. Figure 11 shows these two repeatable diminishing series after enhancement with AY7 fluorescence. The use of a mechanical rig is beneficial as impressions prepared at different forces will exhibit a different interaction with the enhancement reagent. Variations might still be present in the preparation of test footwear impressions when the force is constant. Nonetheless, the use of a test footwear rig assists in limiting some of these variables. 

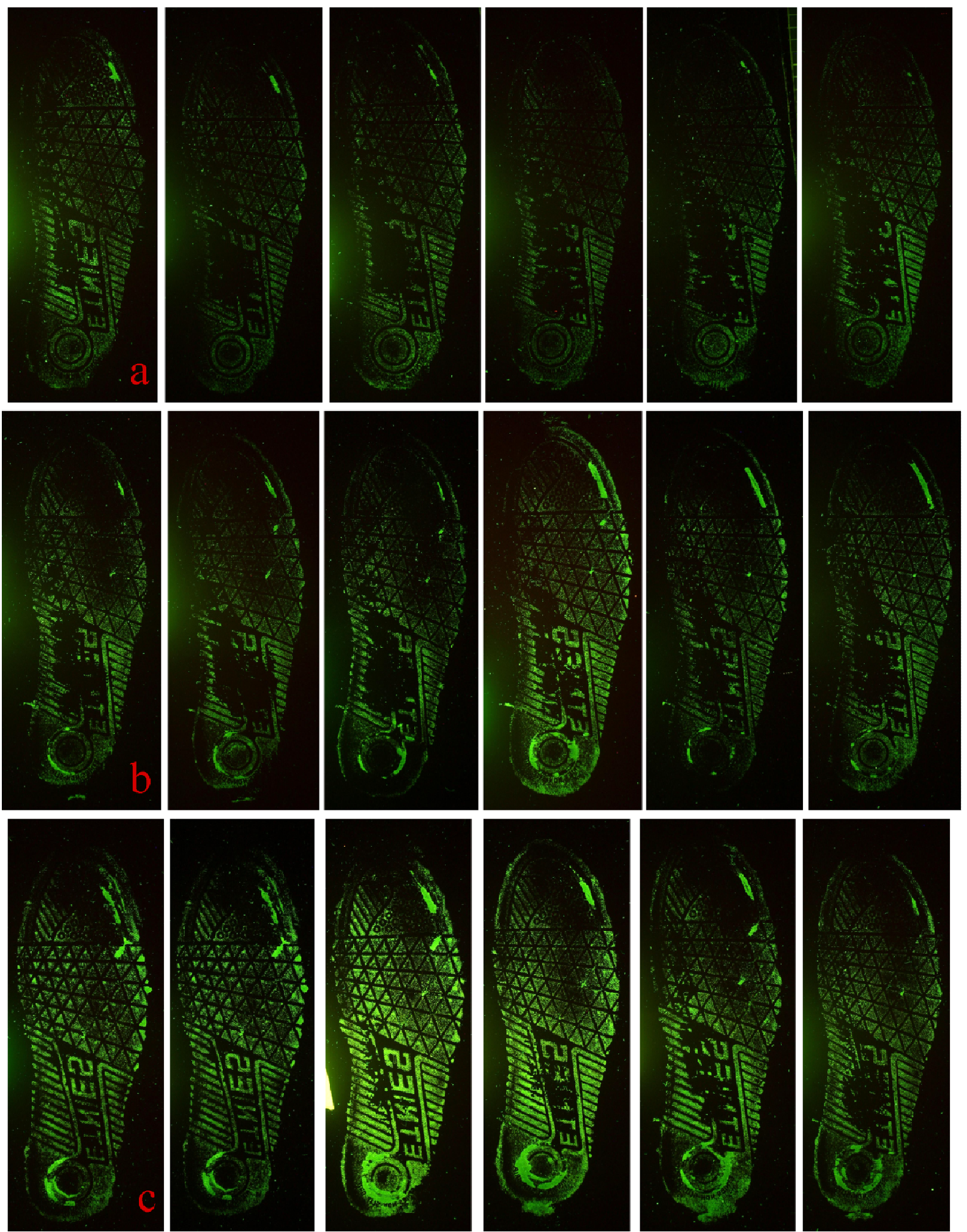

Figure 10 - Six repetitive impressions in blood on black cotton prepared by a mechanical rig and enhanced with AY7 fluorescence using a Mason Vactron Quaser 40 blue light (352-509nm) and viewed with a yellow/orange filter (510nm): (a) low force;

(b) medium force and (c) high force 

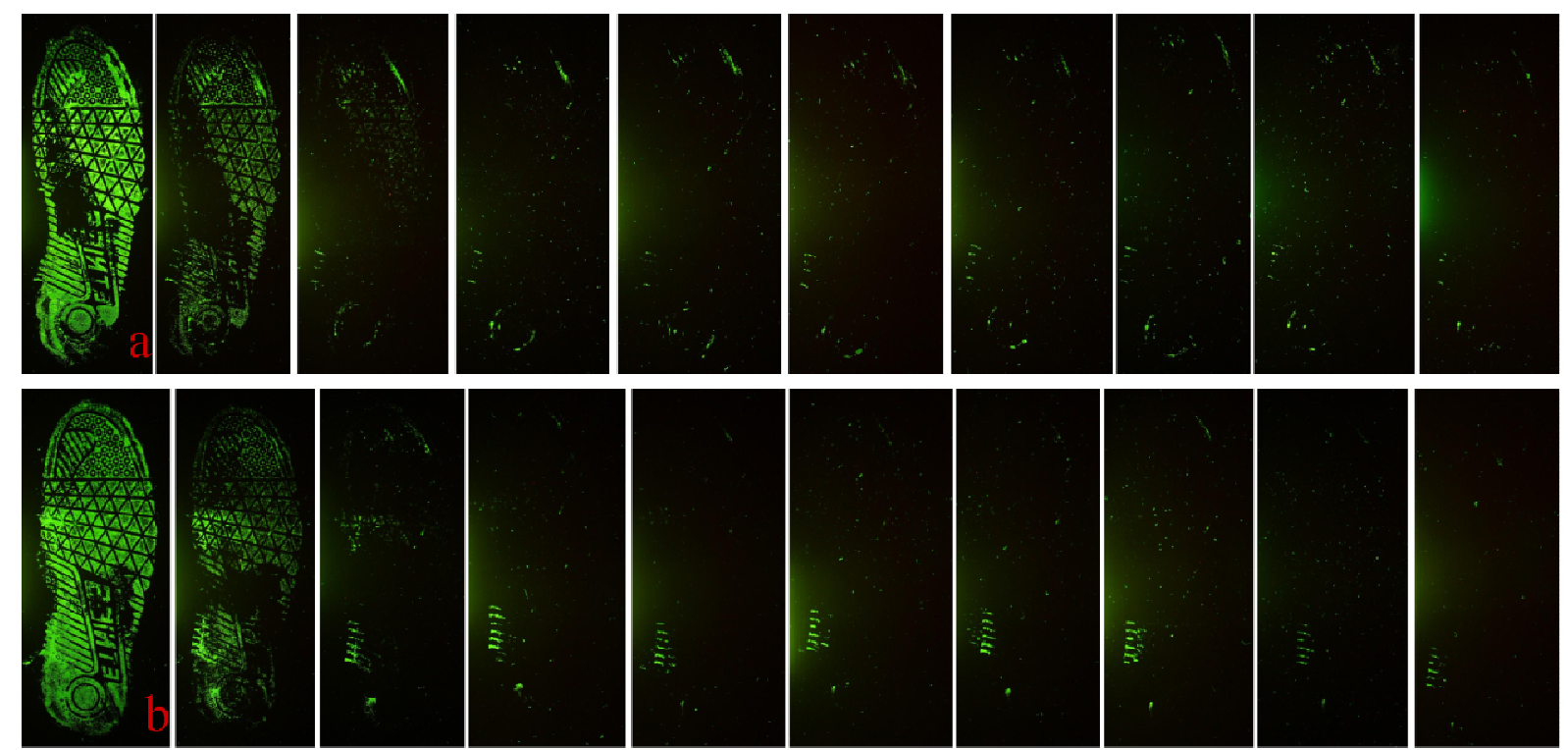

Figure 11 - Two diminishing series of footwear impressions in blood on black cotton prepared using a mechanical rig and enhanced with AY7 fluorescence using a Mason Vactron Quaser 40 blue light $(352-509 \mathrm{~nm})$ and viewed with a yellow/orange filter (510nm): (a) Diminishing Series A and (b) Diminishing Series B

CAST recommends evaluation of different fingerprint enhancement techniques by a diminishing series and splitting the impression in two [31], however, this only allows the direct comparison of two techniques. A comparison of a larger number of techniques would be time consuming as $n^{2}-n$ ( $n$ represent the number of enhancement techniques investigated) depletion series are required for a robust comparison of different enhancement techniques. For example, a diminishing series is split into two where the left part is treated with technique A and the right part with technique B. This is repeated on another series where the left part is now treated with technique $B$ and the right part with technique A. Two sets of depletion series are created to account for any discrepancies arising from uneven deposition pressures [31]. A comparison of 10 techniques for example will result in $10^{2}-10=90$ depletion series. The results obtained from the enhancement of diminishing series of footwear impressions without taking in consideration the variable of force can therefore be misleading. 


\section{CONCLUSION}

The comparison of enhancement techniques for the visualisation of footwear impressions is hindered by uncontrolled variables such as the force applied when the impression is created. In order to compare the efficacy of enhancement techniques in laboratory trials it is essential to be able to minimise the influence of specific factors. Test rigs such as that constructed for this research are essential to this process. The footwear impressions prepared from the test rig limit some of the variables introduced during the production of test footwear impressions and allow for a more robust evaluation of the enhancement techniques to be made. This footwear rig has been utilised for the preparation of test footwear impressions for the evaluation of chemical techniques for the enhancement of footwear impressions in blood, urine and mud on fabric. Such trials can only demonstrate the potential of a specific technique and its operational use must still be evaluated in contextualised trials. This rig was suited for the preparation of test footwear impressions with a stamping action to approximate the action of stamping on clothing. The rig can potentially be utilised to observe bruise patterns on skin produced at different forces. Future work will look at walking actions for the preparation of test footwear impression as well as include the use of other contaminants. 


\section{ACKNOWLEDGEMENTS}

The authors would like to thank CAST, EPSRC and the University of Strathclyde for their continued financial support. This work is also partially funded by the Malta Government Scholarship Scheme. Acknowledgement is also due to the Bioengineering Department at the University of Strathclyde for assistance in building the mechanical rig. We would also like to express our gratitude for all of the volunteers who gave up their time to participate in the study and to the anonymous reviewers who provided useful comments resulting in an improvement of the manuscript. 


\section{REFERENCES}

1. N. Paine, Use of Cyanoacrylate Fuming and Related Enhancement Techniques to Develop Shoe Impressions on Various Surfaces, Journal of Forensic Identification, 48 (5) (1998) 585601.

2. HOSDB, Fingerprint and Footwear Forensics Newsletter, Publication no: 26/08, 2009

3. S. Croft, N. Nic Daeid, K.A. Savage, R. Vallance, R. Ramage, The Enhancement and Recovery of Footwear Marks Contaminated in Soil: A Feasibility Study, Journal of Forensic Identification, 60 (6) (2010) 718-737.

4. A.B.E. Theeuwen, S. Van Barnevald, J.W. Drok, I. Keereweer, B. Lesger, J.C.M. Limborgh, W.M. Naber, R. Schrok, T. Velders, Enhancement of Muddy Footwear Impressions, Forensic Science International, 119 (1) (2001) 57-67.

5. A.B.E. Theeuwen, S. Van Barneveld, J.W. Drok, I. Keereweer, J.C.M. Limborgh, W.M. Naber, T. Velders, Enhancement of Footwear Impressions In Blood, Forensic Science International, 95 (2) (1998) 133-151.

6. W.J. Bodziak, Use of leuco crystal violet to enhance shoe prints in blood, Forensic Science International, 82 (1) (1996) 45-52.

7. D.J. Brundage, Ammonium Thiocyanate: A Successful Technique for Dusty Footwear Impressions, International Symposium on the Forensic Aspects of Footwear and Tire Impression Evidence, Quantico, VA: FBI Academy, 1994

8. D.J. Brundage, Current Use of 8-hydroxyquinoline for Enhancing Footwear Impressions, International Symposium on the Forensic Aspects of Footwear and Tire Impression Evidence, Quantico, VA: FBI Academy, 1994

9. B. Glattstein, Y. Shor, N. Levin, A. Zeichner, Improved Chemical Reagents for the Enhancement of Footwear Marks, International Symposium on the Forensic Aspects of Footwear and Tire Impression Evidence, Quantico, VA: FBI, 1994

10. B. Glattstein, Y. Shor, N. Levin, A. Zeichner, pH Indicators as Chemical Reagents for the Enhancement of Footwear Marks, Journal of Forensic Science, 41 (1) (1996) 23-26.

11. L. Scott Dinkins, Development and Enhancement of Footwear Impressions on Non-Porous Surfaces Using Refrigeration and Cyanoacrylate Fuming, International Symposium on the Forensic Aspects of Footwear and Tire Impression Evidence, Quantico, VA: FBI Academy, 1994

12. S. Someha, Chemical Techniques for the Enhancement of Footwear and Tire Impressions in Japan, International Symposium on the Forensic Aspects of Footwear and Tire Impression Evidence, Quantico, VA: FBI Academy, 1994

13. K. Stow, Direct Lift-Enhancement of Blood-Contaminated Shoe Marks by Leuco Malachite Green-Impregnated Membranes, Science and Justice, 34 (4) (1994).

14. M.J.M. Velders, Fluorescing Mud Prints with Safranin O, 82nd Educational Conference of the International Association for Identification, Danvers, MA, USA, 1997 
15. M.J.M. Velders, Fluorescing Traces in Blood on White Gelatin Lifters with Hungarian Red, 81st Educational Conference of the International Association of Identification, Greensboro, NC, 1996

16. M.J.M. Velders, Mud Prints on Paper Activated for DFO and Cyanoacrylate with Black Gelatin Lifters, 82nd Educational Conference of the International Association for Identification, Danvers, MA, USA, 1997

17. W.J. Bodziak, Footwear Impression Evidence: Detection, Recovery and Examination, 2nd ed, CRC Boca Raton: London, 2000

18. M. Whittle, Gait Analysis: an Introduction, 2nd ed, Butterworth-Heinemann Ltd.: London, 1996

19. P. Riches, A dynamic model of the head acceleration associated with heading a soccer ball, Sports Engineering, 9 (1) (2006) 39-47.

20. K.J. Farrugia, N. Nic Daéid, K.A. Savage, H.L. Bandey, Chemical enhancement of footwear impressions in blood deposited on fabric - Evaluating the use of alginate casting materials followed by chemical enhancement, Science \& Justice, 50 (4) (2010) 200-204.

21. K.J. Farrugia, K.A. Savage, H.L. Bandey, N. Nic Daéid, Chemical Enhancement of Footwear Impressions in Blood on Fabric - Part 1: Protein Stains, Science and Justice, 51 (3) (2011) 99-109.

22. K.J. Farrugia, K.A. Savage, H.L. Bandey, T. Ciuksza, N. Nic Daéid, Chemical Enhancement of Footwear Impressions in Blood on Fabric - Part 2: Peroxidase reagents, Science and Justice, 51 (3) (2011) 110-121.

23. K.J. Farrugia, H.L. Bandey, S. Bleay, N. Nic Daéid, Chemical Enhancement of Footwear Impressions in Urine on Fabric, Forensic Science International, In Print (DOI: 10.1016/j.forsciint.2011.07.020) (2011).

24. K.J. Farrugia, H.L. Bandey, L. Dawson, N. Nic Daeid, Chemical Enhancement of Soil-Based Footwear Impressions on Fabric, Forensic Science International, In Print (2011).

25. S. Fieldhouse, Consistency and reproducibility in fingermark deposition, Forensic Science International, 207 (1-3) (2010) 96-100.

26. O.P. Jasuja, M.A. Toofany, G. Singh, G.S. Sodhi, Dynamics of latent fingerprints: The effect of physical factors on quality of ninhydrin developed prints -- A preliminary study, Science \& Justice, 49 (1) (2009) 8-11.

27. L. Schwarz, An Amino Acid Model for Latent Fingerprints on Porous Surfaces, Journal of Forensic Sciences, 54 (6) (2009) 1323-1326.

28. V. Bowman. 2005. Manual of Fingerprint Development Techniques. 2nd ed. Sandridge, UK: Home Office Scientific Development Branch.

29. Hosdb, Fingerprint Development and Imaging Update, Publication no: 26/03, 2003

30. V.G. Sears, C.P.G. Butcher, L.A. Fitzgerald, Enhancement of Fingerprints in Blood - Part 3: Reactive Techniques, Acid Yellow 7, and Process Sequences, Journal of Forensic Identification, 55 (6) (2005) 741-763. 
31. J.L. Lee, S. Bleay, V.G. Sears, S. Mehmet, R. Croxton, Evaluation of the Dimethylaminocinnamaldehyde Contact Transfer Process and its Application to Fingerprint Development on Thermal Papers, Journal of Forensic Identification, 59 (5) (2009) 545-568. 